needed. We believe, however, that the decreased noise and increased safety offered by these machines over rotary wing aircraft would justify the effort.

Finally, the potential of hot air balloons must not be overlooked. Although rather dependent upon prevailing winds, these devices may hold promise for the future. In old, historic cities, where either blimps or helicopters would intrude upon the city skyline, the hot air balloon would be more aesthetically pleasing. Beyond the aesthetic, however, hot air balloons have other advantages. There is no need to store large amounts of expensive helium. There are many more qualified aircrew for balloons. Most importantly, a preliminary assessment at one institution suggested that in the event of a fossil fuel shortage a custom designed aeromedical hot air balloon could be kept aloft almost indefinitely by health care administration staff. This ability may vary from institution to institution.

To further test these concepts, and as there has been great reluctance to compare helicopter and ground transport directly, we propose a multicentre trial that would compare aeromedical evacuation using helicopters and blimps. Rickshaws, the ultimate "scoop and run" vehicle, would serve as our ground ambulance control. Interested investigators are invited to contact the authors directly.

1 McGinley L. Medical airlifts: rise in crashes draws scrutiny. Wall Street foumal 1986 Oct 27

Reddick EJ. Evaluation of the helicopter in aeromedical transfers. Aviat Space Environ Med 1979;50:168-70.

3 Urdaneta LF, Miller BK, Ringenberg BJ, Cram AE, Scott DH. Role of an emergency helicopter transport service in rural trauma. Arch Surg 1987;122 $992-6$.

4 Schneider S, Borok Z, Heller M, Paris P, Stewart R. Critical cardiac transport: air versus ground. Am $\mathcal{F}$ Emerg Med 1988;6:449-52.

5 Ver Berkmoes R. Aeromedical helicopter accident rate "devastating." American Medical News 1987 Jan 9.

6 Proctor P. Aeromedical aircraft accidents register sharp increase in 1987. Aviation Week and Space Technology 1987 July 13.

(Accepted l February 1989)

\title{
Is an information booklet for patients leaving hospital helpful and useful?
}

\author{
David A Sandler, J R A Mitchell, Alison Fellows, Stephen T Garner
}

\begin{abstract}
Objective-To determine whether a booklet given to patients being discharged from hospital giving details of their admission and treatment increased their knowledge and recall when reviewed in outpatient clinics.
\end{abstract}

Design-Patients alternately allocated to receive a booklet or to serve as controls. Assessment by a questionnaire at first attendance at outpatient clinic after discharge. Data were collected over nine months.

Setting-One general medical and cardiological ward in a large teaching hospital and associated outpatient clinics.

Patients-One hundred and thirty one patients discharged taking at least one drug and scheduled to return to clinic within 12 weeks. Patients stratified by age and by the number of weeks between discharge and outpatient appointment.

Intervention-A booklet was given to 65 patients at discharge from the ward; 66 patients served as controls.

Main results-Of the patients who received the booklet, $56(86 \%)$ knew the names of their drugs, $62(95 \%)$ the frequency of the dose, and $55(85 \%)$ the reasons for taking each drug. The numbers in the control group were $31(47 \%), 38(58 \%)$, and $28(42 \%)$ respectively. These differences were highly significant $(p<0.001)$. Twenty six $(40 \%)$ who received the booklet brought all their drugs to clinic compared with $12(18 \%)$ control patients. Appreciably more of the first group of patients than control patients knew the reason they had been in hospital, and more of the first group indicated that they would take the correct action when their prescribed drugs ran out. Most general practitioners thought that the booklet was a good idea, that it was helpful, and that it was better than the existing interim discharge letter.

Conclusions-Giving patients an information booklet at discharge from hospital appreciably increased the accuracy and thoroughness of their recall of important medical details concerning their illness and its treatment. The booklet was shown to be feasible, helpful in the outpatient clinic, and preferred by most general practitioners.

\section{Introduction}

A recent draft circular from the Department of Health on procedures for discharging patients from hospital ${ }^{1}$ emphasises the need to inform patients of their treatment and follow up; to provide the necessary drugs, ensuring that the patient clearly understands how and when to take the drugs by providing written instructions where possible; and the need to communicate quickly with the patient's general practitioner. Written information has long been considered beneficial in increasing patients' knowledge, but it must be simple and clear. ${ }^{2}$ We have designed a patient information booklet, incorporating the initial hospital discharge letter, the prescription given to the patient at discharge (including brief information about the reason for taking each of the drugs), and clear indications of the arrangements for follow up.

We report the results of a pilot study of the use of this booklet to determine whether it is useful to the patients, their general practitioners, and the hospital doctors who subsequently see the patients in the outpatient clinic.

\section{Methods}

INFORMATION BOOKLET

A four page booklet with a card base was produced. Each page was covered by two similar but detachable sheets of "no carbon required" paper. Thus anything that was written firmly on the top sheet of each page was copied on to the middle page and also on to the card base, which after the top two copies were removed could be folded to form the booklet for the patient.

The first page of the booklet was an adaptation of the usual interim discharge summary giving details of the dates of the patient's admission and discharge, the ward, and the consultant. It also indicated what the patient had been told about why they were in hospital and on the patient's booklet said: "You were in hospital
Correspondence to: $\mathrm{Dr}$ Sandler. 


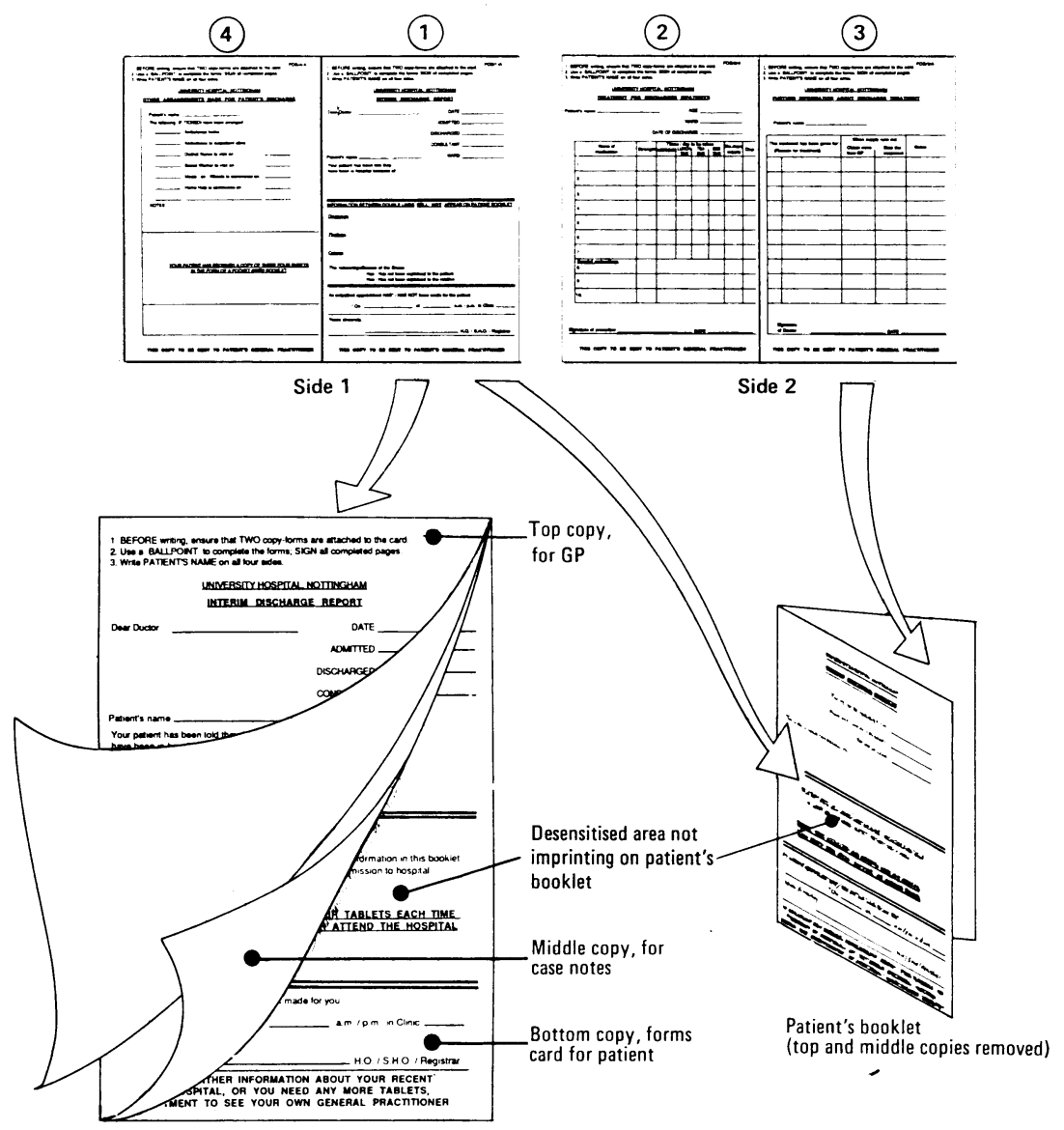

The booklet given to patients on discharge from hospital because of...." The wording of the top and middle copies and the patient booklet was slightly different in other places as well so that it would make sense to both the general practitioner and the patient. The first page also had details about the arrangements for follow up and thus replaced the appointment card for outpatient care. In the centre of this interim summary was a section that did not imprint through to the patient's booklet, and more information could be included on the diagnosis, investigation, and treatment which the medical staff preferred the patient not to see.

On the second and third pages of the booklet was space for prescriptions for drugs to take home which had to be completed to provide the patient with the drugs, thereby serving as an incentive for the other pages to be completed. The identity of the patient was clear and the prescribing doctor had to sign the form thus it was acceptable as a prescription for dispensing. For each drug there were spaces for the name, dose, frequency (related where possible to waking, mealtimes, and bedtime), a simple explanation of the reason for the treatment, and an instruction of what to do when the 14 day supply ran out - that is, to stop the drug or to obtain more from the general practitioner.

The fourth page of the booklet gave details of the "social arrangements" for the patient's return to the community, stating whether ambulances had been arranged to take the patient home or to return to clinic and whether home help, meals on wheels, a district nurse, and so on had been arranged and the date that each would start. This section was to be completed by the nurses who were preparing the patients for discharge. At the bottom of this page was a message in heavy type asking the patients to take the booklet and all their drugs with them when they went to the clinic or saw their general practitioner.

\section{SELECTING PATIENTS}

The study was conducted on one general medical ward among general medical patients and cardiology patients. Any discharged patient who was taking at least one drug and was scheduled to return to one of two medical clinics within 12 weeks of discharge was considered for the study. Patients were stratified by age (up to 65 years or over 65) and by the number of weeks until the clinic visit (up to three, four, five to eight, eight, and over eight) and were alternately allocated to receive a booklet or to serve as a control. Alternate rather than random allocation was necessary as this allowed the study to proceed with the least disruption to the routine on the ward.

\section{DISCHARGE PROCEDURE}

Patients who were allocated to the control group underwent the normal procedure for discharge: once the date of discharge was decided their prescription was written on their inpatient drug chart and dispensed by the pharmacy. The medical staff completed an interim discharge summary and at discharge a nurse gave the patient the drugs, the interim summary in an envelope asking the patient to deliver it to the general practitioner as soon as possible, and the outpatient appointment card which is routinely used in the hospital. This appointment card had the patient's hospital number, the name of the consultant, and the date and time of the appointment. It did not request patients to bring their drugs to the clinic.

For patients who were assigned to the booklet group the booklet was prepared by the medical and clerical staff and sent to the pharmacy for the prescription to be dispensed. When the patient was discharged the top copies of each of the four pages were attached together and given to the patient in an envelope marked for immediate delivery to the patient's general practitioner. In the envelope was a letter of explanation for the general practitioner and a reply paid card asking the general practitioner to appraise the new system. The middle copies of the four pages were retained in the patient's notes to verify that they had been completed, and nursing staff gave the booklet to patients when they were given their drugs.

\section{OUTPATIENT QUESTIONNAIRE}

When patients returned to the outpatient clinic they were interviewed by an investigator (DAS or AF) before their consultation. Patients who failed to attend at the appointed time were sent a further appointment by post and were interviewed at this second appointment. Patients who failed to keep the second appointment were withdrawn from the study. After the questionnaire was briefly explained patients were asked why they had initially been admitted to hospital, which ward they were on, and the name of the consultant in charge of their case. Note was taken of whether the answer was given from memory or whether the patient used a list, the booklet, or the help of an accompanying relative to answer. Patients were assigned to educational groups (group 1-left school as early as possible; group 2-left school with a certificate, O levels, or CSE; group 3-left school with A levels; group 4-went on to higher education but not formally qualified; group 5-higher qualification such as degree or diploma). They were asked for the names of drugs, frequency of dose, and reasons they were taking the drugs, and also what they intended to do or had done when their supply ran out. Note was taken of whether the answers came from memory, the booklet, their own list, an accompanying relative, or tablet bottles. Note was made of the number of drugs that they had brought to clinic. The patients in the booklet group were asked whether they had brought the booklet to the clinic, how often they had read it since being discharged from hospital, and whether anyone else had read it.

The answers given to the questionnaire were later compared with the factual information contained in the 
patients' case notes by two investigators (DAS, JRAM) independently, and a consensus view was reached without reference to whether the patient was in the booklet group or the control group. For the questions about the names, frequency of dose, and reasons for taking the drugs the proportions of correct, incorrect, or unanswered ("couldn't answer" or "didn't answer" were considered together) replies were noted for each patient and divided into categories: correct (or incorrect or unanswered) for all prescribed drugs, for at least half (but not all) of prescribed drugs, for up to half (yet some) of prescribed drugs, and for none.

\section{GENERAL PRACTITIONERS' APPRAISAL}

A letter explaining the study and a reply paid card were sent with all the patients in the booklet group to deliver to their general practitioner asking whether the new system was better or worse than the existing procedure, whether they thought it would help them or their patient, and whether the information booklet was a good idea. They were invited to comment on the new system and asked to state the date the summary arrived at the practice.

\section{STATISTICAL ANALYSIS}

Comparison between the booklet and the control

TABLE I - Details of patients in booklet and control groups

\begin{tabular}{lcc}
\hline & $\begin{array}{c}\text { Booklet } \\
\text { group }(\mathbf{n}=65)\end{array}$ & $\begin{array}{c}\text { Control } \\
\text { group (n=66) }\end{array}$ \\
\hline No (\%) of men & $40(62)$ & $41(62)$ \\
No of women & 25 & 25 \\
Mean age (range) (years) & $61(19-82)$ & $63(31-88)$ \\
No(\%) aged 65 and under & $36(55)$ & $37(56)$ \\
No over age 65 & 29 & 29 \\
Mean No of weeks between & & \\
discharge and survey & $4 \cdot 4$ & $4 \cdot 2$ \\
No(\%) seen within 4 weeks & $51(78)$ & $51(77)$ \\
No(\%) with predominant & & \\
medical condition: & $46(71)$ & $47(71)$ \\
Cardiovascular & $7(11)$ & $6(9)$ \\
Respiratory & $12(18)$ & $13(20)$ \\
Others & $1 \cdot 26$ & $1 \cdot 28$ \\
Mean "educational score" (see text) & $56(86)$ & $57(86)$ \\
No(\%) in educational group 1 & & \\
Drugs: & & \\
No prescribed & 8 & 4 \\
1 & 11 & 8 \\
2 & 12 & 17 \\
3 & 11 & 11 \\
4 & 9 & 14 \\
5 & 14 & 12 \\
>5 & $3 \cdot 81$ & $4 \cdot 07$ \\
Mean & 4 & 4 \\
Median & $1-10$ & $1-9$ \\
Range & & \\
\hline
\end{tabular}

TABLE II - Sources of information used by patients at clinic follow up to answer questionnaire

\begin{tabular}{|c|c|c|c|}
\hline & \multicolumn{2}{|c|}{ Booklet group: } & \multirow{2}{*}{$\begin{array}{l}\text { Control patients } \\
(\text { no booklet }) \\
(n=66)\end{array}$} \\
\hline & $\begin{array}{l}\text { Patients with booklet } \\
\qquad(\mathrm{n}=50)\end{array}$ & $\begin{array}{l}\text { Patients without booklet } \\
\qquad(\mathrm{n}=15)\end{array}$ & \\
\hline Memory alone & 11 & 10 & 40 \\
\hline \multicolumn{4}{|l|}{ Questions about: } \\
\hline Diagnosis & Booklet 2; relative 1 & - & \\
\hline $\begin{array}{l}\text { Name of consultant } \\
\text { Ward }\end{array}$ & $\begin{array}{l}\text { Booklet 5; outpatient card } 2 \\
\text { Booklet } 8\end{array}$ & Own list 1 & $\begin{array}{l}\text { Relative } 1 \text {; own list } 6 \\
\text { Relative 4; own list } 1\end{array}$ \\
\hline Names of drugs & $\begin{array}{l}\text { Booklet } 27 \text {; tablet bottle } 10 \text {; } \\
\text { own list } 1 \text {; relative } 1\end{array}$ & $\begin{array}{l}\text { Tablet bottle 2; own list } 1 \text {; } \\
\text { relative } 1\end{array}$ & $\begin{array}{l}\text { Tablet bottle } 13 \text {; own list } \\
7 \text {; relative } 3\end{array}$ \\
\hline Frequency of dose & Booklet 21 ; tablet bottle 5 & & $\begin{array}{l}\text { Tablet bottle } 7 \text {; own list } 7 \text {; } \\
\text { relative } 2\end{array}$ \\
\hline Reasons for taking drugs & Booklet 11 & & Tablet bottle 1 ; relative 1 \\
\hline
\end{tabular}

TABLE III-Proportion of correct answers given by patients in booklet $(n=65)$ and control $(n=66)$ groups about drugs they were taking. Figures are numbers (and percentages)

\begin{tabular}{|c|c|c|c|c|c|c|c|c|}
\hline \multirow[b]{2}{*}{ Question } & \multicolumn{2}{|c|}{ All correct } & \multicolumn{2}{|c|}{ Over half correct } & \multicolumn{2}{|c|}{ Up to half correct } & \multicolumn{2}{|c|}{ None correct } \\
\hline & Booklet & Control & Booklet & Control & Booklet & Control & Booklet & Control \\
\hline \multirow{3}{*}{$\begin{array}{l}\text { Names of drugs } \\
\text { Frequency of dose } \\
\text { Reasons for taking } \\
\text { drugs }\end{array}$} & $56(86)$ & $31(47)$ & $7(11)$ & $25(38)$ & $2(3)$ & $8(12)$ & 0 & $2(3)$ \\
\hline & $62(95)$ & $38(58)$ & $3(5)$ & $24(36)$ & 0 & $3(5)$ & 0 & $1(1)$ \\
\hline & $55(85)$ & $28(42)$ & $8(12)$ & $29(44)$ & $1(1)$ & $6(9)$ & $1(1)$ & $3(5)$ \\
\hline
\end{tabular}

groups was performed by the $\chi^{2}$ test and comparisons of mean values by the $t$ test.

\section{Results}

One hundred and fifty eight patients were entered in the study, of whom 27 had to be withdrawn (14 from the booklet group, 13 from the control group). Reasons for withdrawal included death (five in booklet group; one in control group), failure to attend at the appointed time (six; seven), patients taking no drugs at discharge (one; two), and clerical error (two; three). Thus 131 patients completed the protocol, 65 in the booklet group and 66 in the control group, and formed the study population.

Table I gives details of age, sex, time between discharge and clinic interview, educational background, and numbers of drugs prescribed for the two groups of patients. There was no significant difference between the mean number of tablets prescribed or the distribution of numbers of drugs between the two groups. All $(100 \%)$ of the patients in the booklet group and $57(86 \%)$ of the control patients correctly stated why they were in hospital. This difference was significant $(p<0.01)$. Seven $(11 \%)$ of the control patients gave an incorrect reason for being in hospital, and two $(3 \%)$ could give no reason. Sixty three $(97 \%)$ patients in the booklet group and $58(88 \%)$ control patients correctly named the consultant, and $59(91 \%)$ and 52 $(79 \%)$ correctly named the ward they had been on, but these differences were not significant. Twenty six $(40 \%)$ booklet patients and $12(18 \%)$ control patients brought all their drugs to clinic, and this difference was significant $(p=0.046)$. A further $13(20 \%)$ booklet patients and $15(24 \%)$ control patients brought some of their drugs, but $26(40 \%)$ and $38(58 \%)$ brought none of their drugs.

Table II gives the sources of information used to answer questions by patients in the booklet group who came to the clinic with and without their booklets and control patients. Thirty nine $(78 \%)$ of the 50 patients who brought their booklet used an aide memoire when answering the questionnaire; 31 of these $(62 \%)$ used their booklet: two for the diagnosis, five for the consultant's name, and eight for the ward. Help with the names of drugs came from 27 booklets, frequency of dose from 21 , and reason for treatment 11 . Five of the 15 patients who did not bring their booklets and 26 of the 66 control patients also used some aid to memory.

Table III gives the proportions of patients in the booklet and control groups who correctly named their drugs. Fifty six $(86 \%)$ patients with a booklet named all of their drugs correctly compared with $31(47 \%)$ control patients. This difference was significant $(\mathbf{p}<0.001)$. If the 27 patients who used their booklet to name their drugs are excluded and the 38 remaining patients are compared with the control patients the difference between the two groups is still significant $(p<0.02)$. None of the patients in the booklet group and only one of the control patients incorrectly named up to half of their drugs; four (6\%) and $18(27 \%)$ could not or did not name up to half of their drugs; and five $(8 \%)$ and $14(21 \%)$ could not or did not name over half of their drugs. Two control patients could not (or failed to) name any of their drugs.

Table III shows the proportions of the two groups of patients who correctly said how often they took each of their drugs. Sixty two (95\%) patients in the booklet group and $38(58 \%)$ control patients gave the correct frequency of use for all of their drugs, and this difference was significant $(p<0 \cdot 001)$. Comparing the controls and the 44 patients who did not use their booklets to answer this question, the difference between the groups remains highly significant 
$(\mathrm{p}<0.001)$. Two booklet patients and seven control patients gave incorrect frequency of dose for up to half of their drugs. A further control patient gave incorrect frequencies for more than half of his prescribed drugs and two control patients gave incorrect frequencies for all of their drugs. Two booklet patients and 18 controls could not (or failed to) give the frequencies of up to half their prescribed medications, and another four $(6 \%)$ control patients did not say how often they took more than half of their prescribed items.

Fifty five (85\%) booklet patients and $28(42 \%)$ control patients gave the correct reason for taking all of their prescribed drugs, and the difference was significant $(\mathrm{p}<0.001)$ (table III). When the 54 patients who did not use their booklet to answer this question are compared with the control patients the difference between the two groups is highly significant $(p<0.001)$. Two booklet patients and nine control patients gave incorrect reasons for taking up to half of their drugs. Five booklet and 24 control patients could not (or did not) give reasons for taking up to half their drugs, three and nine gave no reason for taking over half their drugs, and one and three could not give the reason for taking any of their drugs.

When the prescription ran out $64(98 \%)$ booklet patients and (at least) 48 (73\%) control patients would take the correct action.

Of the 65 patients who had a booklet, $43(66 \%)$ had read it more than once since leaving hospital, $13(20 \%)$ had read it once, and nine $(14 \%)$ had not read it. Spouses of $31(48 \%)$ patients had read the booklet, as had 11 other relatives, 13 general practitioners, and five other people. The copies of 58 of the 65 booklets $(89 \%)$ were found in the case notes and reviewed. The final page of the booklet which referred to the "social arrangements" for discharge from hospital had been used in only two cases - to give details of facilities provided by the district nurse in both and of transport home and to clinic by ambulance in one.

Of the 79 patients who had initially been allocated to the booklet group, $57(72 \%)$ replies were received from their general practitioners. The mean number of days between a patient's discharge from hospital and the summary being delivered to the patient's general practitioner was $4 \cdot 2$ days, median of three days, and range from one (the day of discharge) to 32 days after discharge. Forty one general practitioners (72\%) thought that the system was an improvement, five thought there was no difference, and eight thought it was worse than before mainly because there were four sheets of paper instead of one, thereby creating difficulties with filing (a comment made in 11 replies). Forty six general practitioners $(81 \%$ of respondents) thought that the newer system would help them and their patients, and $52(91 \%)$ thought that the idea of an information booklet was good. Helpful criticism and comments were added by $45(79 \%)$ general practitioners.

\section{Discussion}

Communications between doctors and patients often fail because patients do not understand or remember what they were told. ${ }^{3}$ It has been suggested that patients should receive written information about their treatment $^{2}$ and other aspects of illness and health. ${ }^{4.8}$ The results of a study of generic leaflets giving simple information on the use of antibiotics and non-steroidal anti-inflammatory drugs showed that patients who had leaflets showed better compliance with treatment than those who had no leaflets. ${ }^{9}$ Although leaflets cannot take the place of discussions between patients and doctors or pharmacists, providing patients with written information reinforces the discussion and enhances patient satisfaction. ${ }^{10}$ The results of a survey of elderly patients showed that fewer than half had adequate knowledge about their prescribed drugs, "1 and if patients cannot give an accurate drug history they may not receive suitable treatment.

In busy hospitals with a high turnover of patients patients are often hurriedly and inadequately prepared for the return home and handed their drugs at the door of the ward, sometimes by a junior nurse. So providing written information that patients can study at leisure when at home and discuss with their general practitioner or hospital doctor later should be of benefit. If the general practitioner knows what the patient has been told the general practitioner will be better prepared for the consultation with the patient.

Our two study groups seemed to be well matched. Significantly more patients with booklets than control patients could correctly say why they had been admitted to the ward. Although only two patients referred to the booklet for the answer to this question, all but nine patients had read the booklet at home. There was no difference between the two groups in the numbers who correctly named the consultant in charge. The name of the consultant was written on the appointment cards held by the control patients, and six control patients referred to this to answer the question. Similar numbers in both groups correctly recalled the number of the ward.

More patients with booklets answered the questions about the names of drugs, frequency of dose, and reasons for taking the drugs correctly than control patients. The difference was significant. When patients who used their booklets to answer these questions were excluded from analysis the difference was still significant, suggesting that having a booklet improves a patient's knowledge about their treatment regimen. Incorrect answers were rare, but more control patients did not give answers to the questions. It is interesting that though they had the booklet in clinic 10 of those patients used the tablet bottles to help name their tablets and five used the bottles to help them to recall frequency of dose. Only seven controls referred to their bottles for names of drugs and frequency of dose, and seven had constructed their own list of drugs. Only $26(40 \%)$ patients with booklets and $12(18 \%)$ control patients brought all of their drugs with them to clinic (despite two messages in bold type being imprinted on the booklet asking patients to do this).

Twenty six $(40 \%)$ of the patients with booklets and $38(58 \%)$ control patients brought none of their drugs to clinic. This might have created problems if the patient's recall was poor-which was supported by the number of unanswered questions in this studyespecially if the hospital records were unavailable or out of date, if the clinic doctor did not know the patient, or if the drug treatment had been changed since the patient was discharged. It is usual for hospital doctors to notify the general practitioner if the treatment is changed in clinic, but unusual for a letter to come from the patient's general practitioner if a change has been made. We suggest that all patients should bring with them to hospital all the drugs that they are taking.

We assume that patients will see their general practitioner for a further prescription, but it is not uncommon to see a patient in clinic who thought that their medication was a short course and abruptly stopped treatment when the tablets ran out, sometimes with serious consequences. On the other hand, a discharged patient who is given analgesics or hypnotics for the first few days at home may, because they are in possession of a bottle or list with these drugs on, ask their general practitioner to renew the prescription because it was not made clear that treatment was temporary. A clear indication about the prescriber's 
intentions is invaluable for both the patient and the general practitioner. Our findings show that if patients are given clear instructions about what to do when their drugs are running low they will take the correct course of action.

We do not know why the last page of the booklet was completed in only two cases. The booklets of 58 patients were reviewed: only two district nurses, two journeys by ambulance, and no service from meals on wheels, home helps, or social workers was initiated from the hospital. Perhaps this page was neglected because it did not have to be completed by the medical staff or before the patient was discharged unlike the interim summary and the prescription.

The booklet was read at home by two thirds of patients and many relatives, and 50 of the 65 patients brought it to the clinic with them; $39(78 \%)$ used the booklet or some form of aide memoire during interview, whereas only a third of the patients without their booklet and two fifths of control patients used other sources of help to answer the questions. Having the booklet in the clinic with them may have encouraged patients to use it and other sources of information other than memory to respond to the questionnaire, as well as enhancing the recall of important information.

Nearly three quarters of the local general practitioners responded to our letter about the booklet, $91 \%$ of these considering that the booklet was useful. Three quarters of the respondents made further comments, and those who were unhappy with the system commented on the bulkiness of the four sheets of paper and the legibility or otherwise of some letters. Their comments were helpful and we have now got all the necessary information on to one A4 sheet of paper.

Ellis and others ${ }^{12}$ also provided patients with a "short form," explaining in simple terms the diagnosis, treatment, prognosis, general advice, and arrangements for follow up. As in our study, the patients who were given a leaflet showed a better understanding and recall of this information when later interviewed. We believe that our booklet appreciably enhances patients' recall of details of their recent admission to hospital and the treatment given. The aim of giving patients more information is clearly to improve compliance with drug treatment. This study was not designed to assess compliance, which would be a fruitful area for further research. Patients need to be given information that is simple and easy to understand about their drug treatment, and our booklet does this. Although the cooperation of the junior medical staff was needed to produce the booklet, little extra work was required, particularly as the interim summary and prescriptions have to be written anyway before a patient is discharged. Taking account of the helpful comments we received during this study we have modified the design of the booklet so that all the information is on one side of an A4 sized card which folds into a compact format which can be inserted into a plastic envelope. Since January 1989 this has been given to all patients who were discharged from our unit. It is hoped that we will increase the satisfaction of patients, general practitioners, and clinic doctors and reduce error and misunderstanding.

We thank ward receptionist Christine Morrell and all the junior medical and nursing staff on ward D56, and the nursing staff of Clinic 2, for their patience and cooperation in the conduct of this study; also Professor J R Hampton for permission to study his patients, to all the general practitioners who replied to our letter, and to Mr P Riley for his invaluable statistical advice.

1 Department of Health and Social Security. Discharge of patients from hospita (draft document). London: DHSS, 1988. (EL(88)(P)31.)

2 Anonymous. Drug information for patients: keep it simple [Editorial] BrMed F 1980;280:1393.

3 Ley $\mathrm{P}$. Comprehension, memory and the success of communication with the patient. Fournal of the Institute of Health Education 1972;10:23-9.

4 Anonymous. Telling patients about their medications [Editorial]. Lance 1987;ii: 1064

5 Kay EA, Bailie GR. Educating patients about sublingual glyceryl trinitrate. Pharmaceutical fournal 1987;239:R3.

6 Jenkinson D, Davidson J, Jones S, Hawtin P. Comparison of effects of a selfmanagement booklet and audiocassette for patients with asthma. Br Med $\mathcal{f}$ management book

7 Vaughan B, Taylor K. Homeward bound. Nursing Times 1988;84:28-33.

8 Villar R, Hume AC. Informed orthopaedic consent: fact or fallacy? Yournal of the Medical Defence Union 1988;4:32-3.

9 George CF, Waters WE, Nicholas JA. Prescription information leaflets: a pilo study in general practice. Br Med $\mathcal{J}$ 1983;287:1193-6.

10 George CF. Telling patients about their medicines. Br Med f 1987;294: 1566-7. 11 Joglekar M, Mohanaruban K, Bayer AJ. Medication for the elderly: What do patients know? Br f Clin Pract 1988;42:289-91.

12 Ellis DA, Hopkin JM, Leitch AG, Crofton J. "Doctor's orders": controlled trial of supplementary information for patients. Br Med $\mathcal{F}$ 1979;i:456.

(Accepled 13 fanuary 1989)

\section{WORDS}

sPica Spica (L spica, spike, ear of grain) in a clinical context is a type of bandage in which successive strips of material are applied to the body and the proximal part of a limb, or to the hand and finger. It is so called from a fancied resemblance to an ear of barley. This statement must surely puzzle even those who are familiar with the structure of an ear or spike of the cereal.

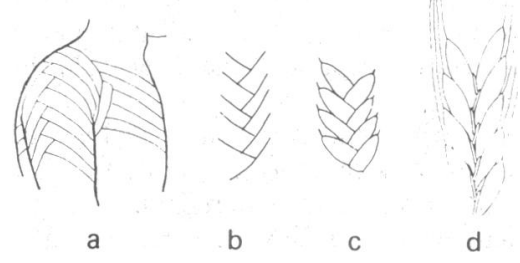

How a bandage is like barley. (a) Spica bandage; $(b)$ inverted view of central area of $(\mathrm{a}) ;(\mathrm{c})$ idealised rendering of $(\mathrm{d}) ;(d)$ diagram of portion of barley spike

The term "ear" has nothing to do with the organ of hearing (Ger Ohr, L auris); it derives from the German Ahre, L acer, sharp, pointed. "Spike" is the accepted botanical term; "ear" is the vernacular. The individual grains are "spikelets." Anything sharp or pointed may be called a spike as, for example, the line on a temperature chart recording a large but brief rise. The illustration shows the connection between the bandage and a spike of barley: $(a)$ the bandage; $(d)$ part of a spike of barley - so far no resemblance. Placed intermediately, $(b)$ shows a selected portion of the bandage shown in $(a)$, but inverted, and (c) an "idealised" modification of $(d)$, with trimmed bristles. The similarity of $(b)$ and $(c)$ is now visible.

The earliest quotation in the Oxford English Dictionary is 1731: "Spica (with surgeons) a band used in hernias," taken from Bailey's Dictionarium Britannicum. A more useful definition is given in E H Knight's The Practical Dictionary of Mechanics (1875): "Spica . . . a form of bandage resembling a spike of barley. The turns of the bandage cross like the letter V, each leaving a portion uncovered."

Evidently, two and a half centuries ago "the man on the Clapham stagecoach" (to modify an old phrase) was familiar enough with the agricultural ambience for "spica" to be pictured in his mind's eye as something resembling the bandage. Nowadays the nearest most doctors get to barley is a glass of beer. And indeed, when viewed through the bottom of the second pint glass, the similarity with the grain is clarified.

COLLAPSE OF STOUT PARTY Young consultant, who fancies himself as an amateur philologist, on a teaching round and at the bedside of a patient with shingles: "The term shingles derives from the Latin cingulum, a belt. But only rarely does it encircle the trunk like a belt. For that reason I prefer to call it zoster. (Turning to Greek student) What does zoster mean in Greek?"

Greek student: "It means a belt, sir."

In the traditional nineteenth century words of the magazine Punch, "Collapse of stout party." - SHAKESPEARE AND VERTIGO Stephano to
Trinculo:

"Prithee, do not turn me about; my stomach is not constant."-The Tempest, II, ii, 120.

The works of William Shakespeare have been intensively explored in medical writing for references to symptoms, diseases, and drugs. Yet I am not aware of any previous reference to vertigo and nausea induced by rotatory movement. Otologists, please note. There's your quote. - B J FREEDMAN 